\title{
A Mobile Phone-Based Support Intervention to Increase Use of Postabortion Family Planning in Cambodia: Cost-Effectiveness Evaluation
}

Jeremy Hill ${ }^{1}$, BA, MSc, MBBS; Jourdan McGinn², MSc; John Cairns ${ }^{2}$, MPhil; Caroline Free ${ }^{3}$, PhD; Chris Smith ${ }^{4,5}$, $\mathrm{PhD}$

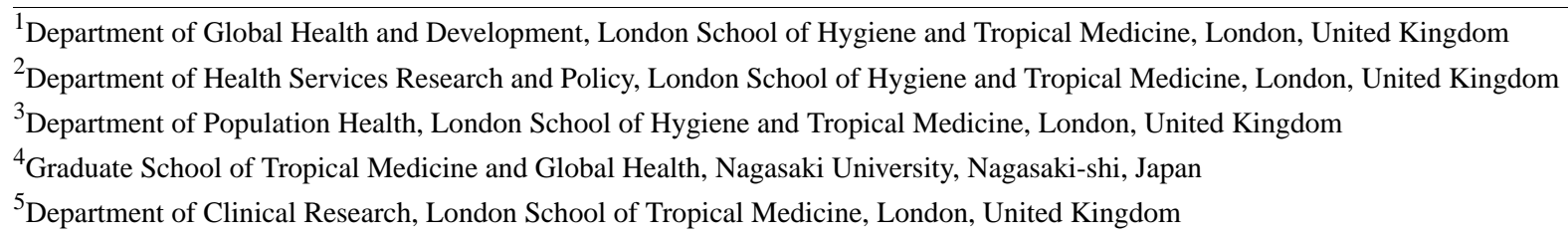

Corresponding Author:

Chris Smith, PhD

Graduate School of Tropical Medicine and Global Health

Nagasaki University

1-12-4, Sakamoto

Nagasaki-shi, 852-8523

Japan

Phone: 818087105309

Email: christopher.smith@1shtm.ac.uk

\section{Abstract}

Background: Despite progress over the last decade, there is a continuing unmet need for contraception in Cambodia. Interventions delivered by mobile phone could help increase uptake and continuation of contraception, particularly among hard-to-reach populations, by providing interactive personalized support inexpensively wherever the person is located and whenever needed.

Objective: The objective of this study was to evaluate the cost-effectiveness of mobile phone-based support added to standard postabortion family planning care in Cambodia, according to the results of the MOTIF (MObile Technology for Improved Family planning) trial.

Methods: A model was created to estimate the costs and effects of the intervention versus standard care. We adopted a societal perspective when estimating costs, including direct and indirect costs for users. The incremental cost-effectiveness ratio was calculated for the base case, as well as a deterministic and probabilistic sensitivity analysis, which we compared against a range of likely cost-effectiveness thresholds.

Results: The incremental cost of mobile phone-based support was estimated to be an additional US $\$ 8160.49$ per 1000 clients, leading to an estimated 518 couple-years of protection (CYPs) gained per 1000 clients and 99 disability-adjusted life-years (DALYs) averted. The incremental cost-effectiveness ratio was US \$15.75 per additional CYP and US \$82.57 per DALY averted. The model was most sensitive to personnel and mobile service costs. Assuming a range of cost-effectiveness thresholds from US \$58 to US \$176 for Cambodia, the probability of the intervention being cost-effective ranged from $11 \%$ to $95 \%$.

Conclusions: This study demonstrates that the cost-effectiveness of the intervention delivered by mobile phone assessed in the MOTIF trial lies within the estimated range of the cost-effectiveness threshold for Cambodia. When assessing value in interventions to improve the uptake and adherence of family planning services, the use of interactive mobile phone messaging and counselling for women who have had an abortion should be considered as an option by policy makers.

Trial Registration: ClinicalTrials.gov NCT01823861; https://clinicaltrials.gov/ct2/show/NCT01823861

(JMIR Mhealth Uhealth 2020;8(2):e16276) doi: 10.2196/16276

\section{KEYWORDS}

mHealth; digital health; cost-effectiveness; contraception; postabortion contraception; postabortion family planning; Cambodia 


\section{Introduction}

Contraception provides significant benefits for the health of women and children, as well as substantial social and economic benefits [1]. An estimated 225 million women in developing countries had an unmet need for contraception in 2014, and if the need were met, it could avert 52 million unintended pregnancies, 24 million abortions (of which around half are unsafe), 70,000 maternal deaths, and 500,000 newborn deaths per year [2].

In Cambodia, over the last decade, progress has been made in reducing an unmet need for contraception. This has coincided with a reduction in maternal, infant, and under-5 mortality [3]. Nonetheless, there is a continued unmet need for contraception in Cambodia. The 2014 Cambodia Demographic and Health Survey reported that among married women aged 15-49 years who wanted to delay a pregnancy by more than 2 years or have no further children, only $56 \%$ were using contraception [3]. There has been a rise in the rate of induced abortions from 21 per 1000 women in 2005 to 28 in 2010 , with $26 \%$ of women having more than one abortion [4].

Interventions delivered by mobile phone could help increase uptake and continuation of contraception, particularly among hard-to-reach populations [5-9]. Compared with face-to-face interventions, mobile phone-based interventions have the advantage that they can provide interactive personalized support inexpensively wherever the person is located and whenever needed [10]. The use of this technology could be of value to women who have had an abortion, as they may face stigma when seeking services or may find it difficult to make informed decisions about family planning at the time of their abortion.

The MOTIF (MObile Technology for Improved Family planning) trial evaluated an intervention delivered by mobile phone to provide postabortion family planning support to women who received safe abortion at Marie Stopes International Cambodia (MSIC) clinics [11]. This trial compared usage of different family planning services during a period of 12 months after abortion among women who were provided with family planning advice via their mobile phones (six automated interactive voice messages over 3 months with a facilitated link to counsellor phone support via a call center and appointment booking if requested) in addition to standard postabortion family planning care provided in accordance with national guidelines, with usage of family planning services among women receiving standard care alone.

The MOTIF intervention was effective at increasing uptake of long-acting reversible contraceptive methods (subdermal implant and intrauterine device [IUD]), which are associated with lower discontinuation rates compared with those of short-acting hormonal methods [12-14]. Long-acting methods are more cost-effective in comparison with short-term methods $[15,16]$, but little evidence exists on the cost-effectiveness of behavior change interventions aimed at improving the uptake of these methods. We aimed to conduct a cost-effectiveness analysis of the MOTIF trial intervention to address this evidence gap.

\section{Methods}

\section{Rationale and assumptions}

We conducted a cost-effectiveness evaluation comparing a mobile phone-based intervention in addition to standard postabortion family planning care with standard care alone, using the results of the MOTIF trial. The methods and results of this trial have been previously published $[11,14]$. In short, standard care included counselling at the clinic, offer of follow-up appointment, and provision of the contact details of an MSIC counselling hotline. Those allocated to the intervention also received six automated interactive voice messages and were provided with phone support from a counsellor depending on their responses to the messages, and optional additional reminder messages were provided to those women who chose to receive oral or injectable contraceptives (a detailed description is provided in Multimedia Appendix 1). The conceptual framework for the cost-effectiveness evaluation is shown in Figure 1. Because postabortion family planning care is delivered over a limited period of time after induced abortion for each individual but the effects of long-acting contraceptive methods may be accrued over the lifespan of the product without further costs being incurred, we chose to model the activities required to deliver postabortion family planning care to a cohort of women along with overhead costs for 1 year only. The time horizon for effects was 10 years, according to the parameters of the Impact2 model as described below. 
Figure 1. Conceptual framework for the service provision model based on the MOTIF trial. Inputs from the MOTIF trial are shown in green. Models used to derive costs and effects are shown in yellow. IUD: intrauterine device; MOTIF: MObile Technology for Improved Family planning; OCP: oral contraceptive pill.

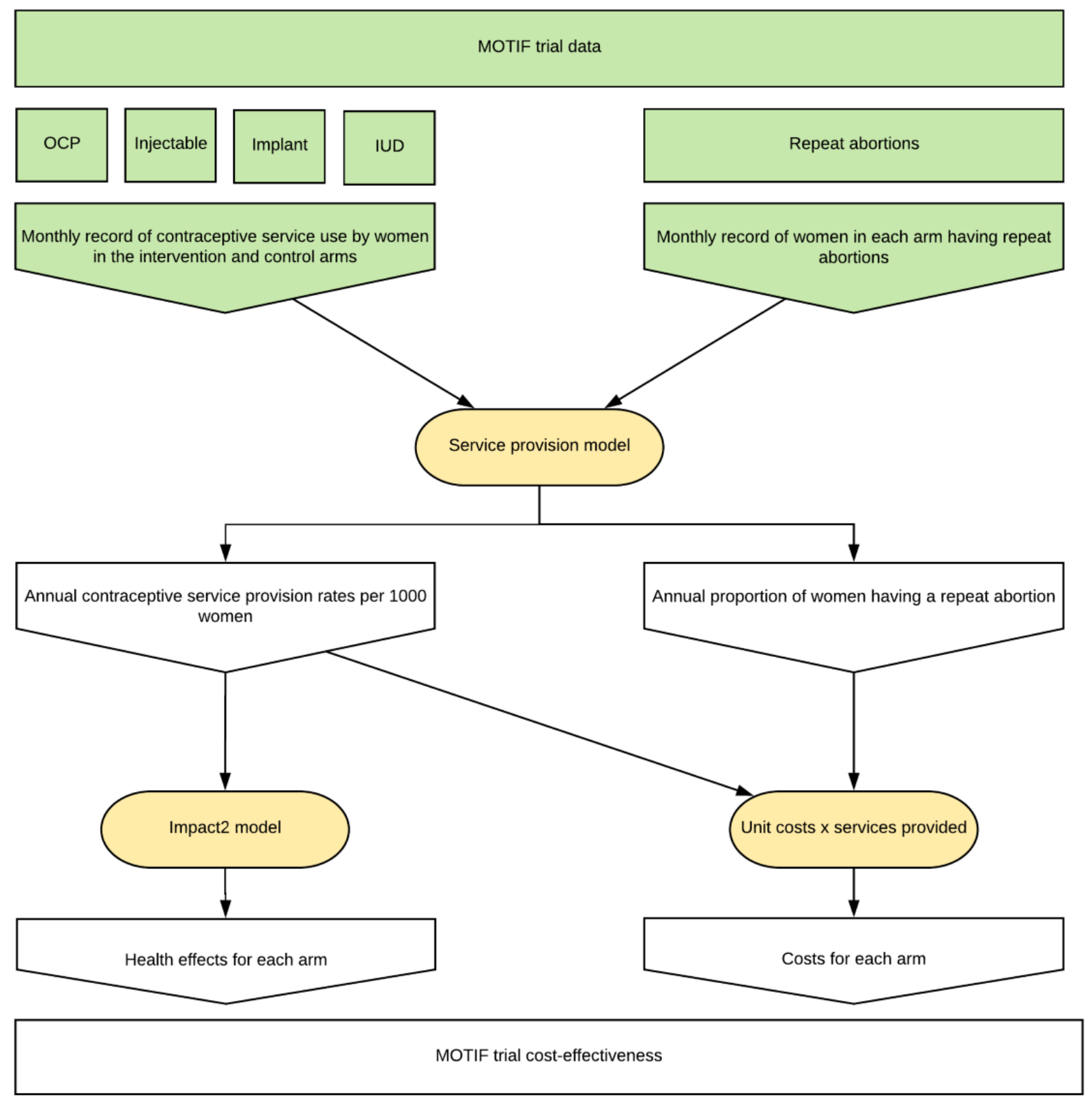

\section{Service Provision Model}

We constructed a model to simulate total contraceptive and abortion services obtained for a single cohort of 1000 women after abortion in the intervention and control arms, using Excel 2016 (Microsoft Corp, Redmond, Washington). This design was chosen to link the empirical service usage data from the MOTIF trial (monthly services per user) to the Impact2 model (annual services per 1000 users). No discounting was applied to costs, because these were modelled to occur during 1 year.

Monthly service provision parameters were taken from $66 \%$ (328/500) of participants remaining in the study at the end of the 12-month follow-up period. Previously published MOTIF findings showed that missing data had a negligible effect on the contraceptive method mix at 12 months [17]. Moreover, some participants in the MOTIF trial used more than one type of contraceptive service (owing to discontinuation or switching). The use of 12-month follow-up parameters allowed us to more accurately reflect this in the overall service provision rates for the simulated cohort of 1000 women in each arm. Model parameters are presented in Table 1. Effects were calculated using contraceptive service parameters only, whereas costs were calculated using both contraceptive service and abortion service parameters. Contraceptive service provision rates and confidence intervals were derived from monthly MOTIF trial data. 
Table 1. Service provision model parameters.

Base Deterministic range $(95 \% \mathrm{CI}) \quad$ Probabilistic distribution

\begin{tabular}{|c|c|c|c|}
\hline \multicolumn{4}{|c|}{ Intervention arm and parameters } \\
\hline \multicolumn{4}{|l|}{ Contraception services $^{a}$} \\
\hline Oral contraceptive pill & 2172 & 2013-2330 & Lognormal \\
\hline Injectable & 558 & $512-604$ & Lognormal \\
\hline Implant & 172 & $123-220$ & Lognormal \\
\hline $\mathrm{IUD}^{\mathrm{b}}$ & 112 & $72-153$ & Lognormal \\
\hline \multicolumn{4}{|l|}{ Abortion services $^{\mathrm{a}}$} \\
\hline Repeat abortion & 47 & $21-91$ & Beta \\
\hline \multicolumn{4}{|l|}{ Control arm parameters } \\
\hline \multicolumn{4}{|l|}{ Contraception services $^{a}$} \\
\hline Oral contraceptive pill & 3308 & 3112-3499 & Lognormal \\
\hline Injectable & 325 & 291-358 & Lognormal \\
\hline Implant & 75 & $42-109$ & Lognormal \\
\hline IUD & 63 & $32-93$ & Lognormal \\
\hline \multicolumn{4}{|l|}{ Abortion services $^{\text {a }}$} \\
\hline Repeat abortion & 69 & $35-120$ & Beta \\
\hline
\end{tabular}

${ }^{\mathrm{a} P e r} 1000$ participants per year.

${ }^{\mathrm{b}}$ IUD: intrauterine device.

\section{Effects}

Effects were estimated using the Marie Stopes Impact2 (version 4) modelling tool (illustrated in Figure 2) using the default settings in "organization" mode for Cambodia in 2013. This tool uses user-provided rates of contraceptive use, which we derived from the service provision model, to estimate effects such as disability-adjusted life-years (DALYs, calculated using 2010 Global Burden of Disease estimates [18]) averted and couple-years of protection (CYPs), taking account of effective usage, discontinuation, and failure rates and wastage for each contraceptive method, as well as country-specific rates for unintended pregnancies, induced abortions, maternal mortality, and under-5 mortality. Consistent with the Global Burden of

Disease Methodology [18], no discounting of effects was applied and age weighting was uniform. Hutterite fertility rates account for the age structure of the population, which we adjusted in the model to reflect the MOTIF sample population. Discounting of fertility over the time horizon was also applied according to Hutterite rates. Effects were calculated to include the service lifespan of each contraceptive method (in the Impact 2 model, we selected 10 years for IUDs and four years for implants). The Impact 2 model includes assumptions based on published research. Of relevance to this study, $31 \%$ of pregnancies worldwide are unintended, and in Asia, $57 \%$ of unintended pregnancies end in abortion [2,19]. The full methodology and assumptions of the Impact 2 model are described elsewhere [20,21]. 
Figure 2. Marie Stopes International Impact 2 model framework. Inputs, outputs, and processes used in the Impact 2 model are illustrated, as they apply to this study. Green: inputs to the model from the MOTIF trial. Yellow: effects reported in this study. Adapted from Weinberger et al [21]. CYPs: couple-years of protection; DALYs: disability-adjusted life-years; LAM: long-acting method; MOTIF: MObile Technology for Improved Family planning.

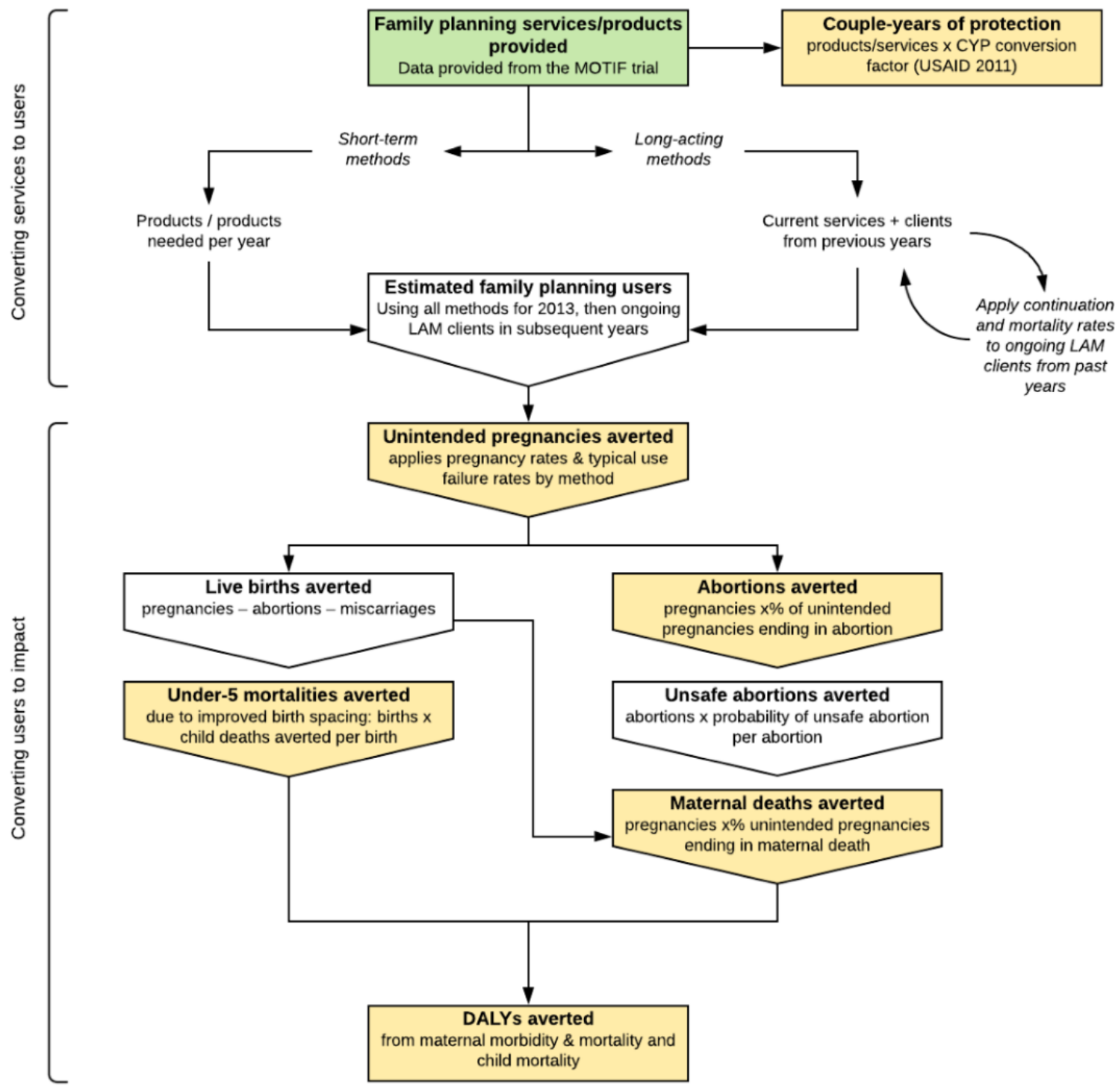

\section{Costs}

The base case analysis was performed from a societal perspective. Costs were collected in 2014 in US dollars (commonly used in Cambodia) and were expressed in constant 2011 purchasing power parity-adjusted US dollars.

For MSIC clinics, provider costs included medical consumables, personnel, and estimates of the time taken to provide each service. To account for overheads, $20 \%$ was added to personnel costs. For non-MSIC clinics, costs for personnel and overheads were not available, and commodity costs were assumed to be the same as those at MSIC clinics. Costs attributable to the intervention included airtime to deliver the mobile phone-based intervention and a proportion of fixed costs (computers and phones). MSIC personnel costs for training and delivery of the intervention were estimated from hourly wages and time spent on the intervention.
User costs included direct medical costs (service fees), direct nonmedical costs, and indirect costs of attending postabortion family planning services for the proportion of women who attended a separate appointment after their initial abortion. The average home-clinic round trip distance was multiplied by the per kilometer average price of motorcycle transport to obtain transport costs. If the client visited a different clinic, the estimated distance was reduced by one-third. Indirect costs to users were attributed to all women irrespective of formal employment status [22]. The time required for users to access each service was the sum of clinical time (reported by MSIC staff) and estimated travel time. Indirect costs attributable to repeat abortions were also included. In Cambodia, injectable and oral contraceptives are widely available at pharmacies, and therefore, costs were assumed to be negligible for clients obtaining these products from non-MSIC clinics. Unit costs and their sources are reported in Table 2 [22-24]. 
Table 2. Unit costs.

$$
\text { Base Deterministic range }{ }^{\mathrm{a}} \quad \begin{aligned}
& \text { Probabilistic Comment/source } \\
& \text { distribution }
\end{aligned}
$$

distribution

Provider costs ${ }^{b}$

MOTIF $^{c}$ intervention costs (per participant)

$\begin{array}{llll}\text { Airtime: voice messages } & 0.79 & 0.39-1.18 & \text { Gamma } \\ \text { Airtime: outgoing phone calls } & 2.16 & 1.08-3.25 & \text { Gamma } \\ \text { Computer } & 1.34 & 0.67-2.01 & \text { Gamma } \\ \text { Phone } & 0.2 & 0.1-0.3 & \text { Gamma }\end{array}$

\section{Family planning service commodities}

Oral contraceptive pill (one cycle)

IUD $^{\mathrm{d}}$

0.29

$0.15-0.44$

Gamma

Gamma

Medical abortion (Mariprist)

$0.4 \quad 0.2-0.6$

$0.35-1.05$

Surgical abortion

2.5-7.5

Injectable contraceptive (one dose) $\quad 0.5$

$0.25-0.75$

Implanted subdermal contraceptive 8

(Femplant)

Long-acting contraceptive device 3 removal

$1.5-4.5$

Personnel (hourly)

Midwife/health care service

Counsellor

\section{User costs $^{\mathrm{a}}$}

\section{Direct costs}

IUD $^{\mathrm{d}}$ insertion
Implant insertion
Injectable (MSIC clinic)
Injectable (pharmacy)
Oral contraceptive pill (MSIC clin-
ic)
Oral contraceptive pill (pharmacy)
IUD removal
Implant removal
Repeat abortion (surgical)
Repeat abortion (medical)

\section{Mobile phone}

Airtime to call a clinic/hotline (per $\min$ )

\section{Transport}

Motorbike travel (per km)

Average distance from clinic to home $(\mathrm{km})$

$\begin{array}{lll}0.22 & 0.11-0.33 & \text { Gamma } \\ 38.2 & 30.1-46.3^{\mathrm{f}} & \text { Gamma }\end{array}$

Actual costs from the MOTIF study Actual costs from the MOTIF study Actual costs from the MOTIF study Actual costs from the MOTIF study

Direct cost reported by an $\mathrm{MSIC}^{\mathrm{e}}$ clinic

Direct cost reported by an MSIC clinic

Direct cost reported by an MSIC clinic

Personal communication with MOTIF trial authors

Direct cost reported by an MSIC clinic

Direct cost reported by an MSIC clinic

Personal communication with MOTIF trial authors

Direct cost reported by an MSIC clinic

Direct cost reported by an MSIC clinic

\section{Indirect costs}




\begin{tabular}{lllll}
\hline & Base & Deterministic range $\mathrm{a}^{\mathrm{a}}$ & $\begin{array}{l}\text { Probabilistic } \\
\text { distribution }\end{array}$ & Comment/source \\
\hline $\begin{array}{l}\text { Gross daily income per capita } \\
\begin{array}{l}\text { Repeat abortion (total household } \\
\text { indirect cost) }\end{array}\end{array}$ & 6.9 & $6.2-7.6^{\mathrm{g}}$ & Gamma & World Bank development data [22] \\
\hline
\end{tabular}

\footnotetext{
${ }^{\mathrm{a}}$ The range used for deterministic analysis was $50 \%$ above and below the base case estimate unless otherwise indicated. This range was then assumed to represent the $95 \%$ confidence interval of the distribution indicated for probabilistic sensitivity analysis.

${ }^{\mathrm{b}}$ Unit costs were combined to calculate the service level costs used in the model.

${ }^{\mathrm{c}}$ MOTIF: MObile Technology for Improved Family planning.

${ }^{\mathrm{d}}$ IUD: intrauterine device.

${ }^{\mathrm{e}}$ MSIC: Marie Stopes International Cambodia.

${ }^{f}$ Range used is the $95 \%$ confidence interval from MOTIF data.

${ }^{\mathrm{g}}$ Range used is $10 \%$ above and below the base case estimate.
}

\section{Cost-Effectiveness}

Incremental cost and utility per 1000 participants were calculated by subtracting the estimated cost and each of the measures of effect (CYPs, pregnancies averted, abortions averted, under-5 mortality, maternal mortality, and DALYs) in the MOTIF intervention arm from those in the standard care arm. The incremental cost-effectiveness ratio (ICER) for each measure of effect was calculated by dividing incremental cost by incremental effect.

\section{Sensitivity Analysis}

To estimate the effect of uncertainty, the model was subjected to deterministic and probabilistic sensitivity analyses [25]. Upper and lower range values were determined for each input parameter. Where possible, $95 \%$ CIs were derived from MOTIF trial data. Else, range values were calculated as $50 \%$ above and below the base case estimate to allow a wide range of uncertainty. The appropriate prior distribution for each parameter was chosen according to 2012 International Society for Pharmacoeconomics and Outcomes Research-Society for Medical Decision Making recommendations, and upper and lower range values were taken as the $95 \%$ CI of that distribution $[26,27]$. We assumed that changes in fees charged to users to access health services would not affect demand for those health services (ie, the price elasticity of demand for the services involved in the MOTIF intervention was zero).

The probabilistic sensitivity analysis consisted of a Monte-Carlo simulation with 1000 iterations randomized according to the probability distribution of each parameter. Contraceptive use outcomes for each iteration were inputted to the Impact 2 model to produce the joint probability distribution for effects. Uncertainty introduced through the Impact2 model itself was not included, because information about parameters used in the Impact 2 model was not available. Simulation results for ICERs assessed using CYPs and DALYs were plotted on the cost-effectiveness plane, and the cumulative probability for cost-effectiveness across a range of cost-effectiveness thresholds was visualized as a cost-effectiveness acceptability curve (CEAC) [28].

To understand the relevance of the cost-effectiveness analysis to decision makers, the results of the base case and sensitivity analyses were compared with the likely range of cost-effectiveness thresholds. Ochalek et al have described a method for empirically deriving cost-effectiveness thresholds in low- and middle-income countries, along with their estimate for a list of countries. The estimated cost-effectiveness threshold for Cambodia using this method ranged from US \$58 to US $\$ 176$ or $12 \%-35 \%$ of the gross domestic product per capita [29].

\section{Scenario Analysis}

To understand the health financing implications of reducing or removing user fees, two scenario analyses were conducted to model the effect on costs from user and provider perspectives. Because user fees represent a transfer from users to providers, from a societal perspective, the net direct effect on costs is zero. For users, we calculated the average estimated cost per client in each scenario. For providers interested in the effect of user fees on cost-effectiveness, we calculated the estimated ICER from the provider perspective.

\section{Results}

The incremental cost of mobile phone-based support from a societal perspective over a 12-month period was an additional US $\$ 8160.49$ per 1000 clients, and it is reported along with costs to providers and users in Table 3. We estimate that an additional 518 CYPs are gained per 1000 clients receiving the MOTIF intervention and that this would avert 180 pregnancies, 103 abortions, and 99 DALYs. The ICER was US $\$ 82.57$ per DALY averted and US $\$ 15.75$ per additional CYP (Table 4). The ICER for DALYs averted fell within the cost-effectiveness threshold range. 
Table 3. Base case cost and effect results for the MOTIF (MObile Technology for Improved Family planning) intervention versus standard of care.

\begin{tabular}{|c|c|c|c|}
\hline & Intervention & Standard care & Incremental value \\
\hline \multicolumn{4}{|l|}{$\operatorname{Costs}^{\mathrm{a}}(\mathrm{US} \$)$} \\
\hline Provider & 4079.74 & -1625.20 & 5704.94 \\
\hline User & $15,906.83$ & $13,451.28$ & 2455.55 \\
\hline Total & $19,986.56$ & $11,826.07$ & 8160.49 \\
\hline \multicolumn{4}{|l|}{ Effects $^{\mathrm{a}}$} \\
\hline Couple-years of protection & 1350.6 & 832.6 & 518.0 \\
\hline Pregnancies averted $^{\mathrm{b}}$ & 441 & 260 & 180 \\
\hline Abortions averted $^{\mathrm{b}}$ & 251 & 148 & 103 \\
\hline $\mathrm{U} 5^{\mathrm{c}}$ mortalities averted ${ }^{\mathrm{b}}$ & 3 & 2 & 1 \\
\hline Maternal mortalities averted ${ }^{b}$ & 0 & 0 & 0 \\
\hline DALYs ${ }^{\mathrm{d}}$ averted & 241.6 & 142.8 & 98.8 \\
\hline
\end{tabular}

${ }^{\mathrm{a}}$ Costs and effects are calculated per 1000 users.

${ }^{\mathrm{b}}$ Rounded to the nearest whole.

${ }^{\mathrm{c}} \mathrm{U}$ : : under five.

${ }^{\mathrm{d} D A L Y s: ~ d i s a b i l i t y-a d j u s t e d ~ l i f e-y e a r s . ~}$

Table 4. Base case incremental cost-effectiveness ratio (ICER) results for the MOTIF (MObile Technology for Improved Family planning) intervention.

\begin{tabular}{ll}
\hline Effect & ICER (US \$ per unit of effect) \\
\hline Couple-years of protection & 15.75 \\
Pregnancies averted & 45.22 \\
Abortions averted & 79.33 \\
U5 $^{\text {a }}$ mortalities averted & 7659.96 \\
Maternal mortalities averted & $-{ }^{b}$ \\
DALYs & averted \\
\hline
\end{tabular}

${ }^{\mathrm{a}} \mathrm{U}$ : under five.

${ }^{b}$ No maternal mortalities were estimated to have been averted in either arm; therefore, no ICER calculation is possible.

${ }^{c}$ DALYs: disability-adjusted life-years.

Results of the deterministic sensitivity analysis are presented as a tornado plot in Figure 3. The base case model was most sensitive to personnel costs, costs for phone calls and voice messages, the uptake and delivery of long-acting contraceptive methods (IUD or implant), and the percentage added to reflect overhead costs. For all parameters, the ICER estimated using upper and lower range values fell within the cost-effectiveness threshold range. 
Figure 3. Tornado plot of deterministic sensitivity analysis using MOTIF intervention model parameters. For each parameter, the ICER was recalculated taking the upper and then lower deterministic range value. ICER ranges are centered on the ICER point estimate of US $\$ 82.57$ per DALY averted. DALYs: disability-adjusted life-years; ICER: incremental cost-effectiveness ratio; IUD: intrauterine device; MOTIF: MObile Technology for Improved Family planning; MSIC: Marie Stopes International Cambodia; OC: oral contraceptive.

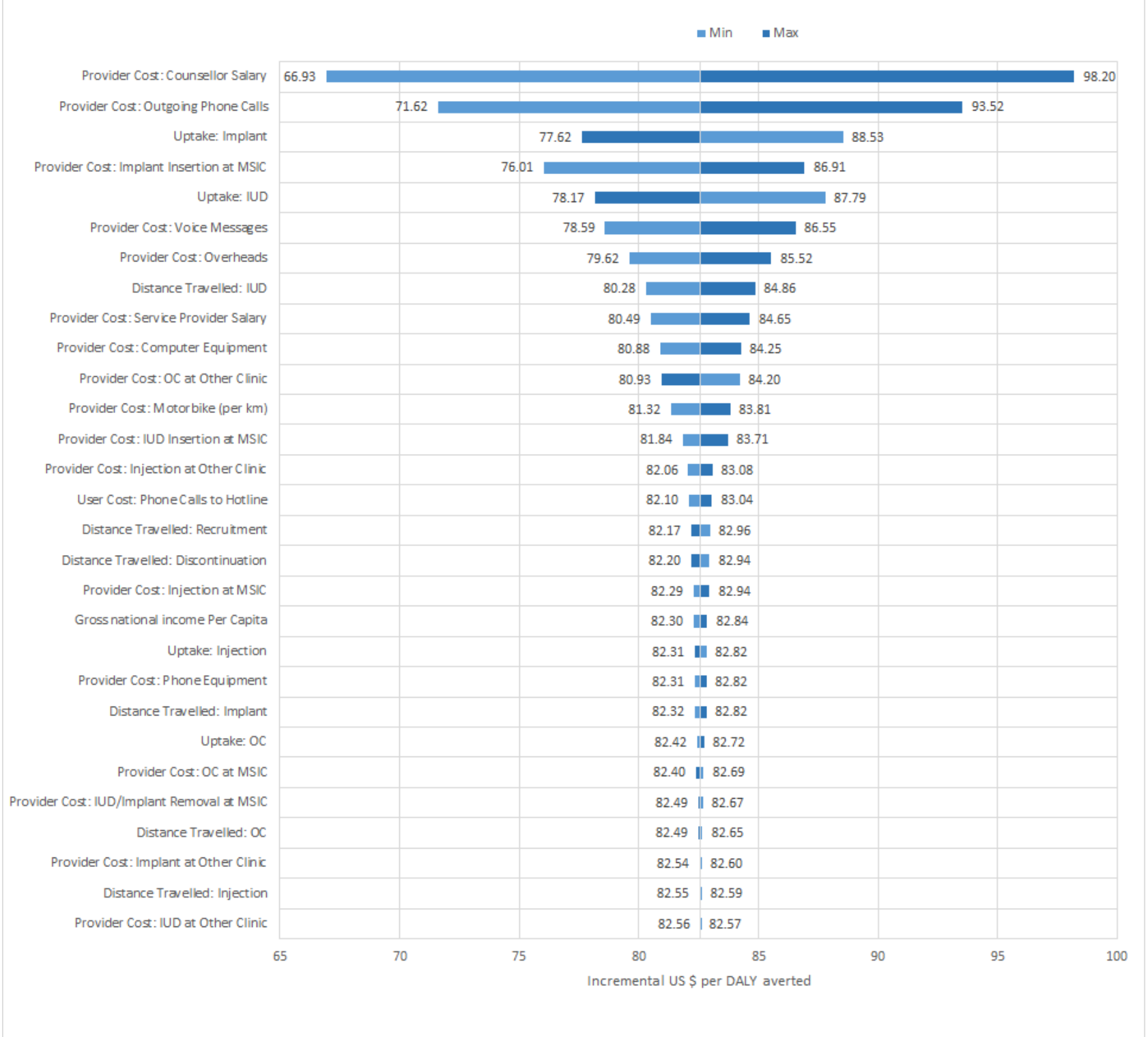

Simulations recorded for probabilistic sensitivity analysis are presented on the cost-effectiveness plane for DALYs averted and CYPs in Figures 4 and 5. Results for the two measures of effect appear very similar, albeit on a different horizontal scale, because the Impact 2 modelling tool estimates approximately five times the number of CYPs achieved as DALYs averted, for any set of randomized inputs. On the plane for DALYs, most simulations lie within the cost-effectiveness threshold range.
CEACs for the two measures of effect are shown in Figures 6 and 7. The CEAC measured per DALY averted shows that the intervention has an $11 \%$ probability of being cost-effective at the lower end of the cost-effectiveness range (US \$58) and a 95\% probability at the upper end of the range (US \$176). A $50 \%$ probability of being cost-effective would be achieved at a cost-effectiveness threshold of US $\$ 83$ per DALY averted and about US \$16 per CYP. 
Figure 4. Monte-Carlo simulation results plotted on the cost-effectiveness plane, with effects measured in DALYs averted. Linear demarcations of the upper and lower bounds for the cost-effectiveness threshold for DALYs averted are included for comparison. DALYs: disability-adjusted life-years; MOTIF: MObile Technology for Improved Family planning.

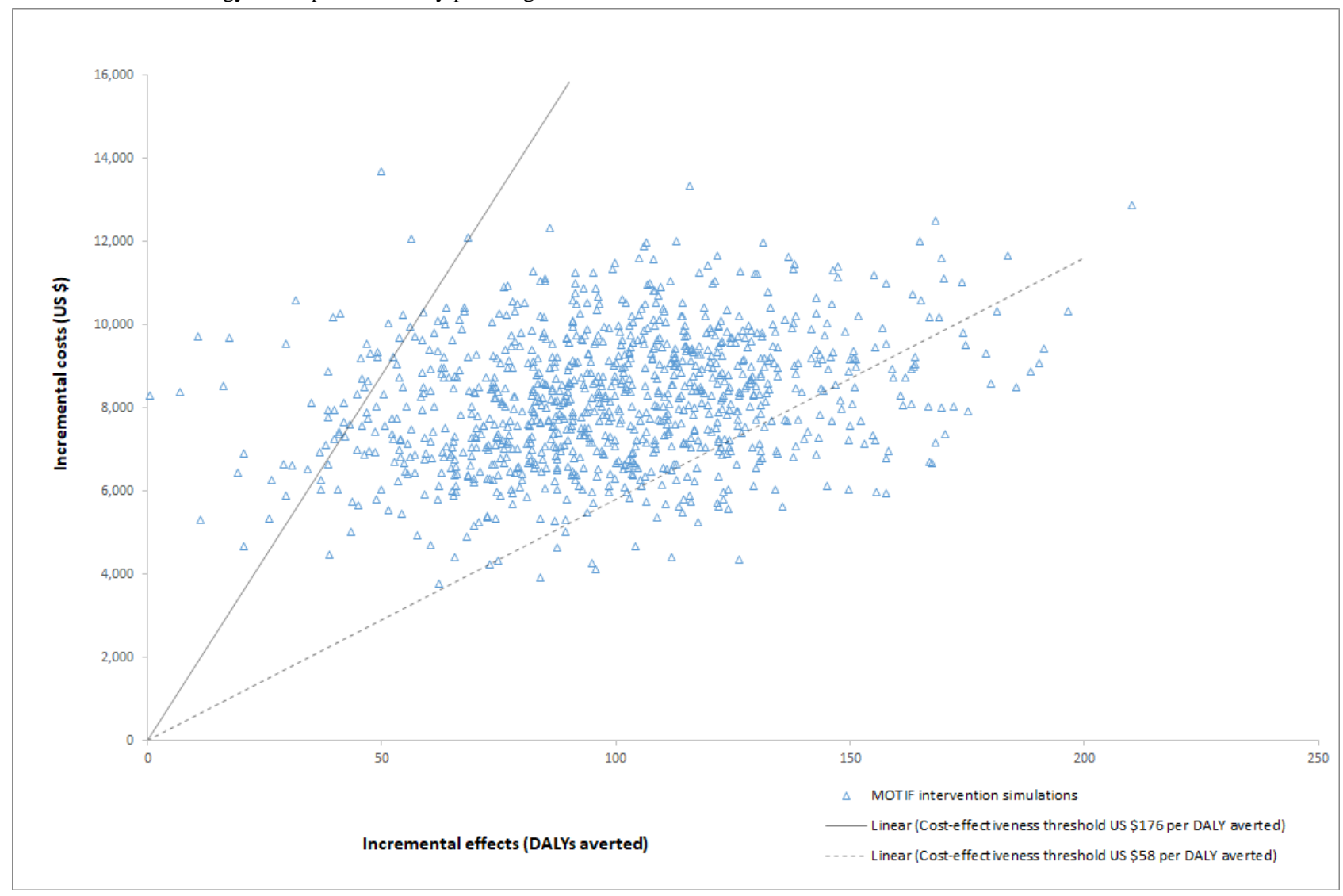

Figure 5. Monte-Carlo simulation results plotted on the cost-effectiveness plane, with effects measured in CYPs. CYPs: couple-years of protection.

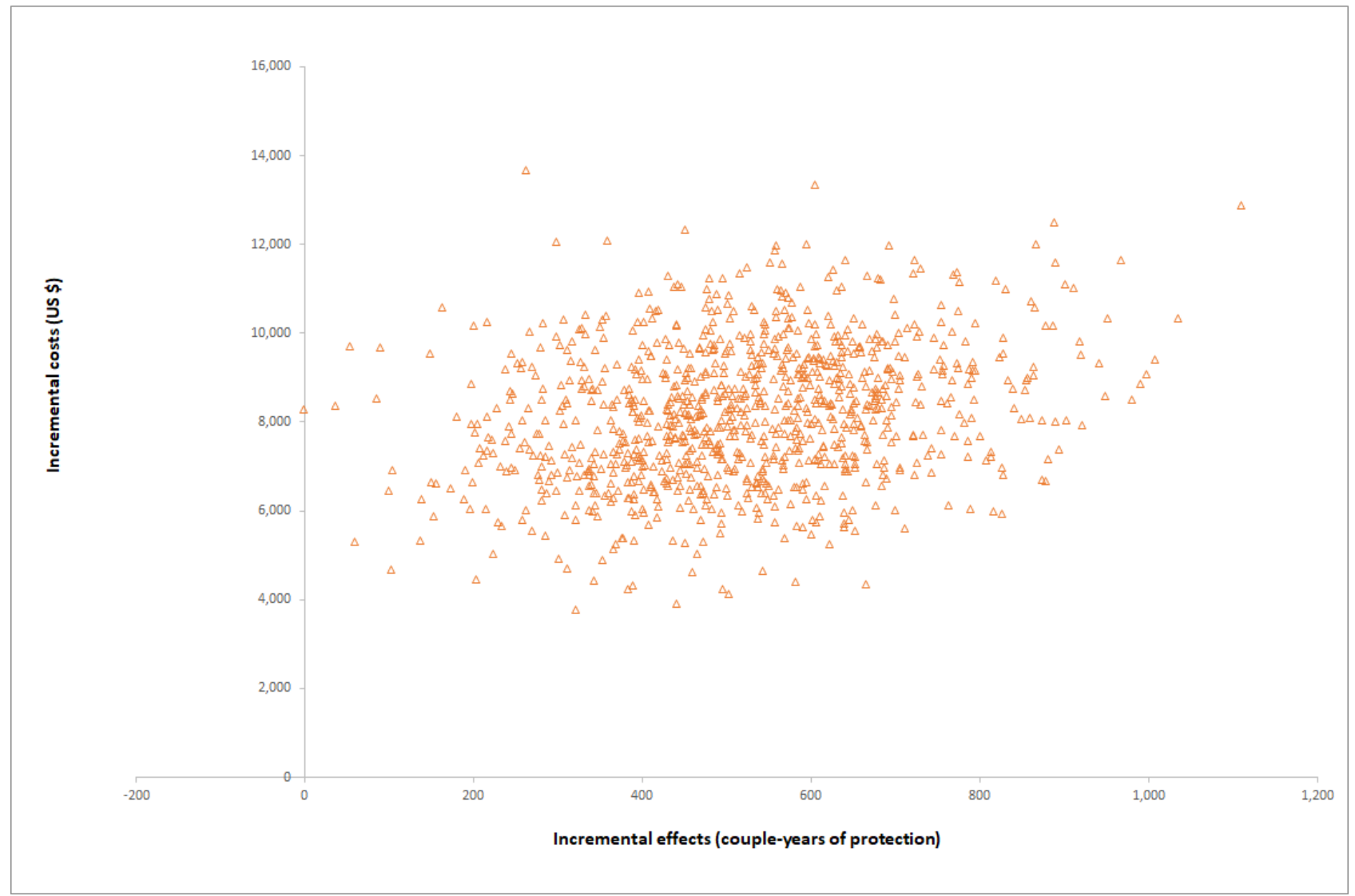


Figure 6. Cost-effectiveness acceptability curve derived from Monte-Carlo simulations of MOTIF intervention results, with effects measured in DALYs averted. DALYs: disability-adjusted life-years; MOTIF: MObile Technology for Improved Family planning.

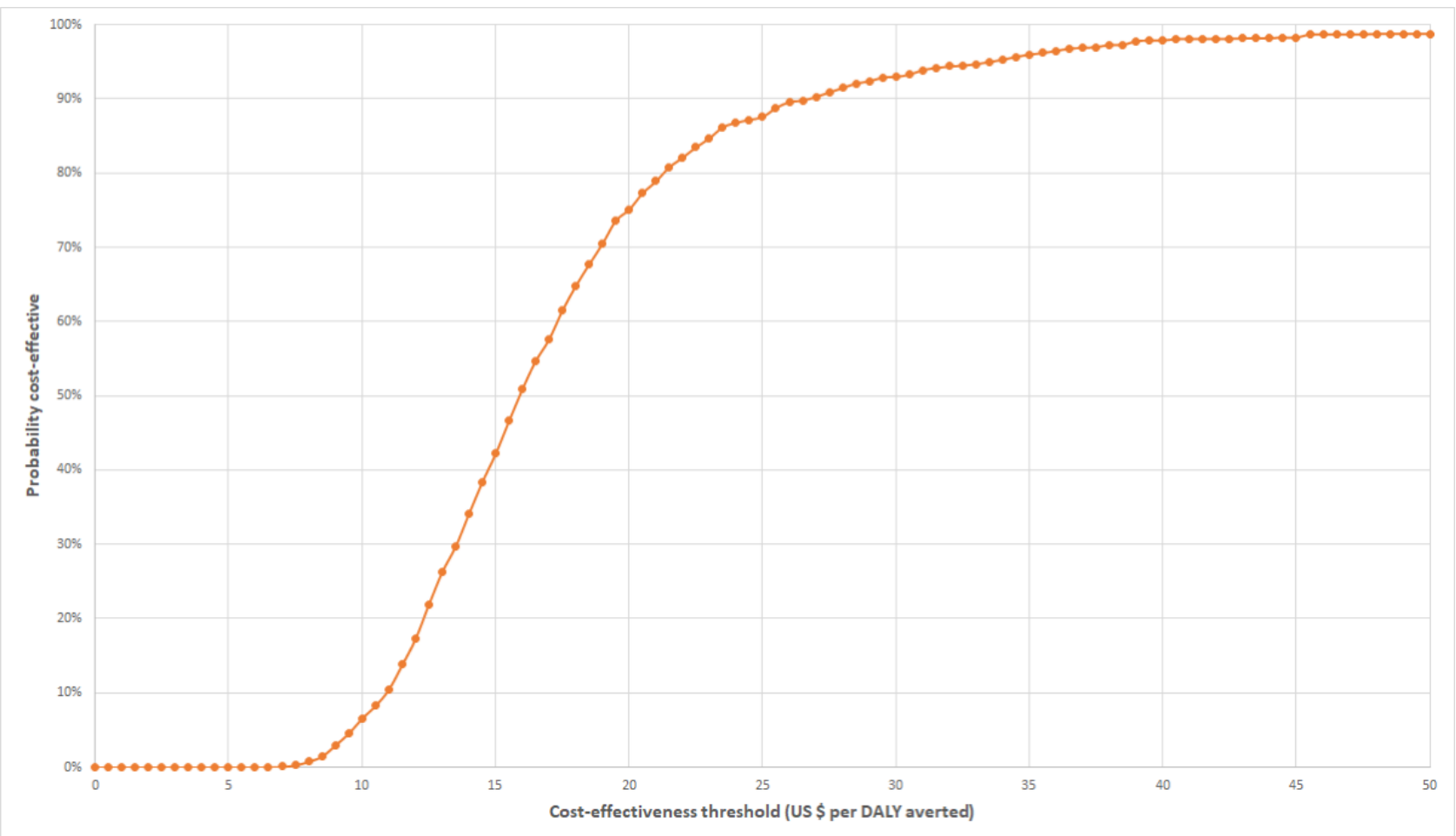

Figure 7. Cost-effectiveness acceptability curve derived from Monte-Carlo simulations of MOTIF intervention results, with effects measured in CYPs averted. CYPs: couple-years of protection; MOTIF: MObile Technology for Improved Family planning.

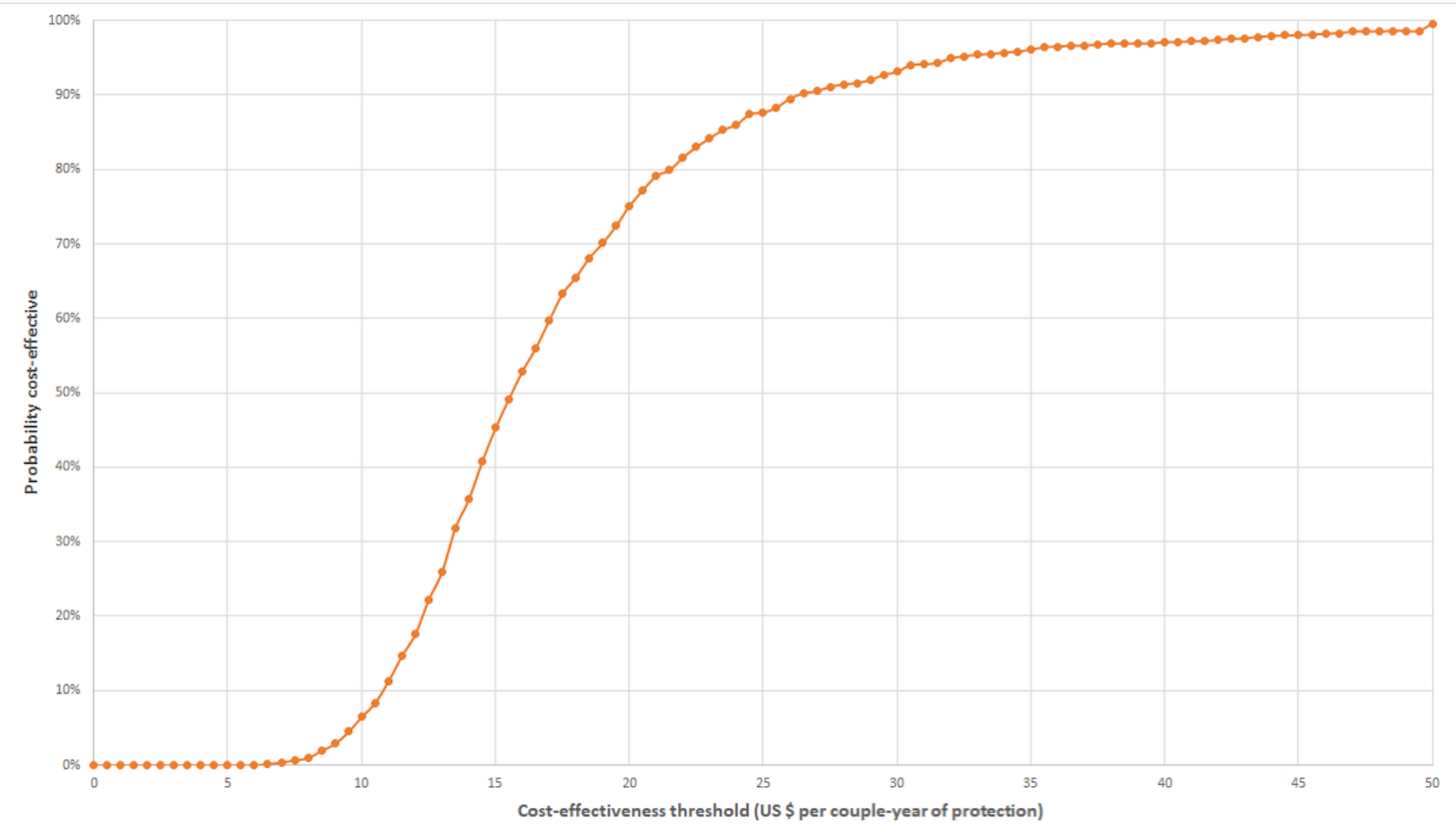

Average costs from a user perspective and cost-effectiveness from a provider perspective, with either $50 \%$ or no user fees, are compared with costs and cost-effectiveness from a societal perspective in Table 5. With decreasing user fees, the average cost to users participating in the MOTIF intervention decreased from US \$15,906.83 to US \$8772.00 per 1000 participants (from
$80 \%$ to $44 \%$ of the cost of the program from a societal perspective). The ICER from the provider's perspective increased from US $\$ 57.72$ to US $\$ 77.58$ per DALY averted. With the removal of user fees and by considering the provider perspective, the MOTIF intervention remained within the range of cost-effectiveness thresholds for Cambodia. 
Table 5. Costs for users and providers in scenarios involving variable user fees.

\begin{tabular}{|c|c|c|c|c|}
\hline & Base case & Scenario 1 ( $50 \%$ user fees) & Scenario 2 (no user fees) & Societal perspective ${ }^{\mathrm{a}}$ \\
\hline \multicolumn{5}{|c|}{ Total cost per 1000 participants, user perspective (US \$) } \\
\hline Intervention & $15,906.83$ & $12,339.41$ & 8772.00 & $19,986.56$ \\
\hline Standard care & $13,451.28^{\mathrm{c}}$ & $10,864.97$ & 8278.66 & $11,826.07$ \\
\hline Incremental & 2455.55 & 1474.44 & 493.34 & 8160.49 \\
\hline \multicolumn{5}{|c|}{ ICER $^{d}$, provider perspective (US \$ per unit of effect) ${ }^{b}$} \\
\hline Couple-years of protection & 11.01 & 12.91 & 14.80 & 15.75 \\
\hline Pregnancies averted & 31.61 & 37.05 & 42.49 & 45.22 \\
\hline Abortions averted & 55.46 & 65.00 & 74.54 & 79.33 \\
\hline $\mathrm{U}^{\mathrm{e}}$ mortalities averted & 5355.02 & 6275.95 & 7196.88 & 7659.96 \\
\hline Maternal mortalities averted & ${ }_{-}^{\mathrm{f}}$ & - & - & - \\
\hline DALYs ${ }^{\mathrm{g}}$ averted & 57.72 & 67.65 & 77.58 & 82.57 \\
\hline
\end{tabular}

${ }^{\mathrm{a}}$ Costs and ICERs from a societal perspective are included for reference. These results remain constant in each scenario, as the user fee represents a transfer from users to providers, but a net zero change from a societal perspective.

${ }^{\mathrm{b}}$ Results are presented as total cost (direct and indirect) from a user perspective and ICER from a provider perspective to reflect the outcome of interest for the respective groups. Changes in demand resultant from the imposition of user fees have not been modelled as part of the scenario analysis.

${ }^{\mathrm{c}}$ Under standard care with $100 \%$ user fees, the program provides income to providers.

dCER: incremental cost-effectiveness ratio.

${ }^{\mathrm{e}} \mathrm{U}$ : under five.

${ }^{\mathrm{f}}$ No maternal mortalities were estimated to have been averted in either arm; therefore, no ICER calculation is possible.

g DALYs: disability-adjusted life-years.

\section{Discussion}

\section{Principal Findings}

This study demonstrates that the cost-effectiveness of the intervention delivered by mobile phone assessed in the MOTIF trial lies within the estimated range of the cost-effectiveness threshold for Cambodia. When assessing value in interventions to improve the uptake and adherence of family planning services, the use of interactive mobile phone messaging and counselling for women who have had an abortion should be considered as an option by policy makers. The MOTIF trial demonstrated that women randomized to an intervention delivered by a mobile phone were more likely to use long-acting contraceptive methods. Although these methods are known to be more cost-effective, the results of this study extend the evidence to show that an intervention delivered by a mobile phone favoring these methods is itself cost-effective.

\section{Strengths of the Study}

This study has several strengths. Many of the cost and effect parameters are derived from trial and intervention delivery data rather than estimates from the literature, therefore improving the external validity of cost-effectiveness estimates within the Cambodian context. The use of the Impact 2 model allows for replicable measurements of effects and comparison across studies. The cost-effectiveness estimates of the base case, the deterministic sensitivity analysis, and $96 \%$ of the probabilistic simulations fell within the chosen range of cost-effectiveness thresholds, and the threshold range was drawn from empirically derived cost-effectiveness threshold ranges, which are intended to realistically reflect what health systems are willing to pay $[29,30]$. We also included scenario analyses relating to the application of user fees for family planning services. Together, the design and results of this analysis might provide useful information when adapting the findings of the study to implementation, where affordability for public sector providers is likely to be an important factor.

Another strength of the study lies in the timely and important contribution to the literature linking innovations in mobile phone-based delivery with the delivery of family planning services. With the proliferation of mobile technology in the most rural and remote areas of the globe, there is great opportunity for harnessing mobile technology to reach women with life-saving health information. This study adds to the emerging body of knowledge about how to most effectively and efficiently achieve this aspect.

\section{Limitations of the Study}

Deterministic testing indicated that estimated ICERs were particularly sensitive to counsellor personnel costs, estimated as a product of salary and time. However, these time estimates were not collected systematically, and they do not account for a run-in period of lower efficiency. Our estimates are therefore most relevant to a scaled-up intervention or a scenario where support by mobile phone is added to existing activities, for example, an established call center, where run-in time is reduced to a minimum. Process evaluations (unpublished) of the MOTIF trial intervention suggested that the link to a counsellor who 
could make an appointment if requested was a key to the success of the intervention, so programmatic implementation of a similar intervention should include these components. Although a component of training time was included in costs to deliver the intervention, the cost of ongoing technical support and training was not included. Sensitivity testing also indicated that the proportion of overheads attached to personnel costs produced a large change in ICER in comparison with other parameters. Overheads were not estimated as individual unit costs as part of the study, and thus, the approximation of overheads as a proportion of personnel costs could be improved.

Many of the cost parameters were estimated by personal communication with MOTIF study authors and staff, limiting the external validity of our results in other regions of Cambodia. Further, a range of $50 \%$ above and below the point estimate was used for sensitivity analyses. This was intended to capture a broad range of uncertainty in estimated costs, although it still may not accurately represent the cost of family planning services elsewhere in the country.

In the MOTIF trial, contraceptive use outcomes were self-reported by participants. Although this is the standard in family planning research, self-reported measures have been shown to overestimate contraceptive use and are susceptible to recall bias [31]. These outcomes were used as inputs for the Impact 2 model, so the effects estimated using this model would be affected in a similar way to contraceptive use outcomes in the MOTIF trial.

The Impact 2 modelling tool is based on a number of assumptions linking contraceptive service provision to health outcomes. Although these assumptions are founded in a strong evidence base, the evidence is drawn from the survey data of all women of reproductive age, and it is possible that patterns of contraceptive use and decision-making behavior might differ in a postabortion population. Although the model settings for Cambodia were used and the modelled population was adjusted to match the age distribution of participants in the MOTIF trial, it is possible that differences between the trial population and the population used to inform the Impact 2 model, for example, the socioeconomic distribution, might result in errors. The authors of the Impact 2 methodology note that estimates of under-5 mortality may be particularly unreliable owing to limited data on linkages among contraception use, birth spacing, and child mortality [20]. Despite these limitations, CYPs and DALYs are well-known measures of effect, and a focus on these outcomes increases the interpretability of this study in comparison with other interventions.

\section{Comparison With Existing Research}

There is extensive related literature in the areas of mobile health (mHealth) and economic evaluation [32,33], of which, a number of studies relate specifically to family planning interventions. In a 2016 study by Mangone et al, a modelling approach was used to estimate the costs of a scaled-up mHealth intervention for reproductive health in Tanzania. This did not include a component of effectiveness; however, it did propose models for cost recovery based on mobile phone charges, in which costs were consistent with the findings of this analysis [34]. Zakiyah et al conducted a systematic review of economic evaluations of family planning interventions in low- and middle-income countries, identifying nine eligible studies, and in all of these, family planning interventions were found to be highly cost-effective [35]. There have been two systematic reviews of mobile phone-based interventions for family planning services; one focused on adults and the other focused on adolescents $[9,10]$. Both these reviews identified limited but promising evidence that mHealth interventions are effective for improving uptake and adherence to contraception, noting that there was sparse data from low- and middle-income countries. Our study is consistent with these findings and adds an important piece of economic evidence supporting the implementation of interventions delivered by mobile phone for family planning in these settings.

\section{Implications for Future Research and Health Policy}

With the proliferation of cheap and accessible mobile phones and network access, even in rural and remote locations, there is substantial interest in taking advantage of mobile innovations to aid the delivery of family planning programs. The MOTIF trial intervention, which was recently included as a digital high-impact practice in family planning behavior change, is an example of a scalable mobile innovation [36]. However, it is difficult to make a case for scaled-up digital health interventions without an assessment of cost-effectiveness. This study demonstrates that the cost-effectiveness of the intervention in the MOTIF trial lies within the range of the cost-effectiveness threshold for Cambodia, thus supporting decision makers to include mHealth interventions in future family planning policies in Cambodia.

The sensitivity and scenario analyses included in this study provide useful details for health policy makers. Personnel costs and mobile phone costs have the greatest effects on the cost-effectiveness of the intervention and provide a useful focus for the business case that would accompany a scaled-up mHealth intervention. The cost and effect parameters used in this analysis were collected in a trial environment, whereas modest economies of scale could be achieved with wider implementation, for example, through automation of some call center tasks and bulk pricing agreements with network operators. From a user perspective, removal of user fees for services almost halved the average cost per participant in the intervention group. The effect of user fees on participation in family planning services was assumed to be zero in this study. Although there is likely to be some effect in practice, evidence from low- and middle-income countries suggests that contraceptive services are inelastic with respect to price [37]. These areas of uncertainty and opportunity are all fruitful areas for further economic and operational research.

Although this study provides useful evidence to support the cost-effectiveness of the MOTIF intervention, research to test and compare the cost-effectiveness of other interventions for improving the uptake of postabortion family planning services would improve the generalizability of this study to other settings.

\section{Conclusion}

This study demonstrates that the use of an intervention delivered by a mobile phone to provide postabortion family planning 
counselling was cost-effective for increasing CYPs and for preventing pregnancy and abortion. It also provides a basis for further research on how this emerging technology can improve access to family planning services.

\section{Acknowledgments}

We thank all clients and clinic staff who participated in the study. We thank Ly Sokhey, Uk Vannak, Kathryn Church, Anisa Berdellima, and Aisha Dasgupta at Marie Stopes International and Ties Hoomans at LSHTM for comments on previous versions and collecting cost data during the trial.

\section{Authors' Contributions}

CS, JM, and JC conceptualized the study; JM and JH performed formal analysis; CS, JM, JH, and JC were responsible for the methodology; JC, CF, and CS supervised the study; JM, JH, and CS prepared the original draft; and JM, JH, JC, CF, and CS reviewed and edited the manuscript.

\section{Conflicts of Interest}

None declared.

\section{Multimedia Appendix 1}

Detailed description of the MOTIF intervention.

[DOCX File, 13 KB-Multimedia Appendix 1]

\section{References}

1. Cleland J, Conde-Agudelo A, Peterson H, Ross J, Tsui A. Contraception and health. Lancet 2012 Jul 14;380(9837):149-156. [doi: 10.1016/S0140-6736(12)60609-6] [Medline: 22784533]

2. Singh S, Darroch JE, Ashford LS. Guttmacher Institute. New York: Guttmacher Institute; 2014. Adding It Up 2014: The Costs and Benefits of Investing in Sexual and Reproductive Health URL: https://www.guttmacher.org/report/ adding-it-costs-and-benefits-investing-sexual-and-reproductive-health-2014 [accessed 2020-01-26]

3. National Institute of Statistics/Cambodia, Directorate General for Health/Cambodia, ICF International. The DHS Program. Phnom Penh, Cambodia: National Institute of Statistics/Cambodia, Directorate General for Health/Cambodia, and ICF International; 2015. Cambodia Demographic and Health Survey 2014 URL: http://dhsprogram.com/publications/ publication-FR312-DHS-Final-Reports.cfm [accessed 2020-01-26]

4. Fetters T, Samandari G. Abortion incidence in Cambodia, 2005 and 2010. Glob Public Health 2015;10(4):532-544. [doi: 10.1080/17441692.2014.992453] [Medline: 25649162]

5. Källander K, Tibenderana JK, Akpogheneta OJ, Strachan DL, Hill Z, Asbroek AA, et al. Mobile health (mHealth) approaches and lessons for increased performance and retention of community health workers in low- and middle-income countries: a review. J Med Internet Res 2013;15(1):e17 [FREE Full text] [doi: 10.2196/jmir.2130] [Medline: 23353680]

6. Free C, Phillips G, Galli L, Watson L, Felix L, Edwards P, et al. The effectiveness of mobile-health technology-based health behaviour change or disease management interventions for health care consumers: a systematic review. PLoS Med 2013;10(1):e1001362 [FREE Full text] [doi: 10.1371/journal.pmed.1001362] [Medline: 23349621]

7. Castaño PM, Bynum JY, Andrés R, Lara M, Westhoff C. Effect of daily text messages on oral contraceptive continuation: a randomized controlled trial. Obstet Gynecol 2012 Jan;119(1):14-20. [doi: 10.1097/AOG.0b013e31823d4167] [Medline: 22143257]

8. Hou MY, Hurwitz S, Kavanagh E, Fortin J, Goldberg AB. Using daily text-message reminders to improve adherence with oral contraceptives: a randomized controlled trial. Obstet Gynecol 2010 Sep;116(3):633-640. [doi: 10.1097/AOG.0b013e3181eb6b0f] [Medline: 20733446]

9. L'Engle KL, Mangone ER, Parcesepe AM, Agarwal S, Ippoliti NB. Mobile Phone Interventions for Adolescent Sexual and Reproductive Health: A Systematic Review. Pediatrics 2016 Sep;138(3). [doi: 10.1542/peds.2016-0884] [Medline: 27553221]

10. Smith C, Gold J, Ngo TD, Sumpter C, Free C. Mobile phone-based interventions for improving contraception use. Cochrane Database Syst Rev 2015;6:CD011159. [doi: 10.1002/14651858.CD011159.pub2] [Medline: 26115146]

11. Smith C, Vannak U, Sokhey L, Ngo TD, Gold J, Khut K, et al. MObile Technology for Improved Family Planning Services (MOTIF): study protocol for a randomised controlled trial. Trials 2013 Dec 12;14:427 [FREE Full text] [doi: 10.1186/1745-6215-14-427] [Medline: 24330763]

12. Ali MM, Cleland J. Contraceptive switching after method-related discontinuation: levels and differentials. Stud Fam Plann 2010 Jun;41(2):129-133. [Medline: 21466113]

13. Ali MM, Park MH, Ngo TD. Levels and determinants of switching following intrauterine device discontinuation in 14 developing countries. Contraception 2014 Jul;90(1):47-53 [FREE Full text] [doi: 10.1016/j.contraception.2014.03.008] [Medline: 24792145] 
14. Smith C, Ngo TD, Gold J, Edwards P, Vannak U, Sokhey L, et al. Effect of a mobile phone-based intervention on post-abortion contraception: a randomized controlled trial in Cambodia. Bull World Health Organ 2015 Dec 01;93(12):842-50A [FREE Full text] [doi: 10.2471/BLT.15.160267] [Medline: 26668436]

15. Chiou CF, Trussell J, Reyes E, Knight K, Wallace J, Udani J, et al. Economic analysis of contraceptives for women. Contraception 2003 Jul;68(1):3-10. [doi: 10.1016/s0010-7824(03)00078-7] [Medline: 12878280]

16. Henry N, Schlueter M, Lowin J, Lekander I, Filonenko A, Trussell J, et al. Cost of unintended pregnancy in Norway: a role for long-acting reversible contraception. J Fam Plann Reprod Health Care 2014 Dec 23;41(2):109-115. [doi: 10.1136/jfprhc-2014-100878]

17. Smith C, Jarvis C, Free C. Assessing loss to follow-up in the MObile Technology for Improved Family Planning (MOTIF) randomised controlled trial. Trials 2017 Dec 01;18(1):577 [FREE Full text] [doi: 10.1186/s13063-017-2316-6] [Medline: 29191231]

18. Murray CJ, Vos T, Lozano R, Naghavi M, Flaxman AD, Michaud C, et al. Disability-adjusted life years (DALYs) for 291 diseases and injuries in 21 regions, 1990-2010: a systematic analysis for the Global Burden of Disease Study 2010. Lancet 2012 Dec 15;380(9859):2197-2223. [doi: 10.1016/S0140-6736(12)61689-4] [Medline: 23245608]

19. Sedgh G, Singh S, Hussain R. Intended and unintended pregnancies worldwide in 2012 and recent trends. Stud Fam Plann 2014 Sep;45(3):301-314 [FREE Full text] [doi: 10.1111/j.1728-4465.2014.00393.x] [Medline: 25207494]

20. Weinberger MB, Fry K, Boler T, Hopkins K. Estimating the contribution of a service delivery organisation to the national modern contraceptive prevalence rate: Marie Stopes International's Impact 2 model. BMC Public Health 2013;13 Suppl 2:S5 [FREE Full text] [doi: 10.1186/1471-2458-13-S2-S5] [Medline: 23902699]

21. Weinberger M, Fry K, Hopkins K. Marie Stopes International. London: Marie Stopes International; 2015. Impact 2 v3: An innovative tool for estimating the impact of reproductive health programmes-methodology paper URL: https://mariestopes. org/resources/impact-2-methodology-paper/ [accessed 2020-01-26]

22. The World Bank. World Development Indicators: Cambodia URL: https://data.worldbank.org/country/cambodia [accessed 2018-02-08]

23. Rozemuller B, Thou P, Yan S. International Labour Organization. Phnom Penh, Cambodia: International Labour Organisation, Ministry of Rural Development Cambodia; 2002. Rural Transporters: A Survey of Transport Businesses in Rural Cambodia URL: http://www.ilo.org/emppolicy/pubs/WCMS ASIST 8399/lang--en/index.htm [accessed 2020-01-26]

24. Potdar R, Fetters T, Phirun L. Initial loss of productive days and income among women seeking induced abortion in Cambodia. J Midwifery Womens Health 2008;53(2):123-129. [doi: 10.1016/j.jmwh.2007.06.010] [Medline: 18308261]

25. Drummond MF, Sculpher MJ, Torrance GW, O'Brien BJ, Stoddart GL. Methods For The Economic Evaluation Of Health Care Programmes. Oxford, UK: Oxford University Press; 2005.

26. Briggs AH, Claxton K, Sculpher MJ. Decision Modelling For Health Economic Evaluation. Oxford, UK: Oxford University Press; 2006.

27. Caro JJ, Briggs AH, Siebert U, Kuntz KM, ISPOR-SMDM Modeling Good Research Practices Task Force. Modeling good research practices--overview: a report of the ISPOR-SMDM Modeling Good Research Practices Task Force--1. Value Health 2012;15(6):796-803 [FREE Full text] [doi: 10.1016/j.jval.2012.06.012] [Medline: 22999128]

28. Barton GR, Briggs AH, Fenwick EA. Optimal cost-effectiveness decisions: the role of the cost-effectiveness acceptability curve (CEAC), the cost-effectiveness acceptability frontier (CEAF), and the expected value of perfection information (EVPI). Value Health 2008;11(5):886-897 [FREE Full text] [doi: 10.1111/j.1524-4733.2008.00358.x] [Medline: 18489513]

29. Ochalek J, Claxton K, Lomas J. CHE Research Paper. York, UK: Centre for Health Economics, University of York; 2015. Cost Per DALY Averted Thresholds for Low- and Middle-Income Countries: Evidence From Cross Country Data URL: http://www.york.ac.uk/media/che/documents/papers/researchpapers/CHERP122 cost DALY LMIC threshold.pdf [accessed 2020-01-26]

30. Woods B, Revill P, Sculpher M, Claxton K. Country-Level Cost-Effectiveness Thresholds: Initial Estimates and the Need for Further Research. Value Health 2016 Dec;19(8):929-935 [FREE Full text] [doi: 10.1016/j.jval.2016.02.017] [Medline: 27987642]

31. Stuart GS, Grimes DA. Social desirability bias in family planning studies: a neglected problem. Contraception 2009 Aug;80(2):108-112. [doi: 10.1016/j.contraception.2009.02.009] [Medline: 19631784]

32. Guerriero C, Cairns J, Roberts I, Rodgers A, Whittaker R, Free C. The cost-effectiveness of smoking cessation support delivered by mobile phone text messaging: Txt2stop. Eur J Health Econ 2013 Oct;14(5):789-797 [FREE Full text] [doi: 10.1007/s10198-012-0424-5] [Medline: 22961230]

33. Iribarren SJ, Cato K, Falzon L, Stone PW. What is the economic evidence for mHealth? A systematic review of economic evaluations of mHealth solutions. PLoS One 2017;12(2):e0170581 [FREE Full text] [doi: 10.1371/journal.pone.0170581] [Medline: 28152012]

34. Mangone ER, Agarwal S, L'Engle K, Lasway C, Zan T, van Beijma H, et al. Sustainable Cost Models for mHealth at Scale: Modeling Program Data from m4RH Tanzania. PLoS One 2016;11(1):e0148011 [FREE Full text] [doi:

10.1371/journal.pone.0148011] [Medline: 26824747] 
35. Zakiyah N, van Asselt AD, Roijmans F, Postma MJ. Economic Evaluation of Family Planning Interventions in Low and Middle Income Countries; A Systematic Review. PLoS One 2016;11(12):e0168447 [FREE Full text] [doi:

10.1371/journal.pone.0168447] [Medline: 27992552]

36. High-Impact Practices in Family Planning. Washington, DC: USAID; 2018. Digital Health for Social and Behavior Change: New technologies, new ways to reach people URL: http://www.fphighimpactpractices.org/briefs/digital-health-sbc/ [accessed 2020-01-26]

37. Korachais C, Macouillard E, Meessen B. How User Fees Influence Contraception in Low and Middle Income Countries: A Systematic Review. Stud Fam Plann 2016 Dec 17;47(4):341-356 [FREE Full text] [doi: 10.1111/sifp.12005] [Medline: $\underline{27859370]}$
Abbreviations
CEAC: cost-effectiveness acceptability curve
CYPs: couple-years of protection
DALYs: disability-adjusted life-years
ICER: incremental cost-effectiveness ratio
IUD: intrauterine device
MOTIF: MObile Technology for Improved Family planning
MSIC: Marie Stopes International Cambodia

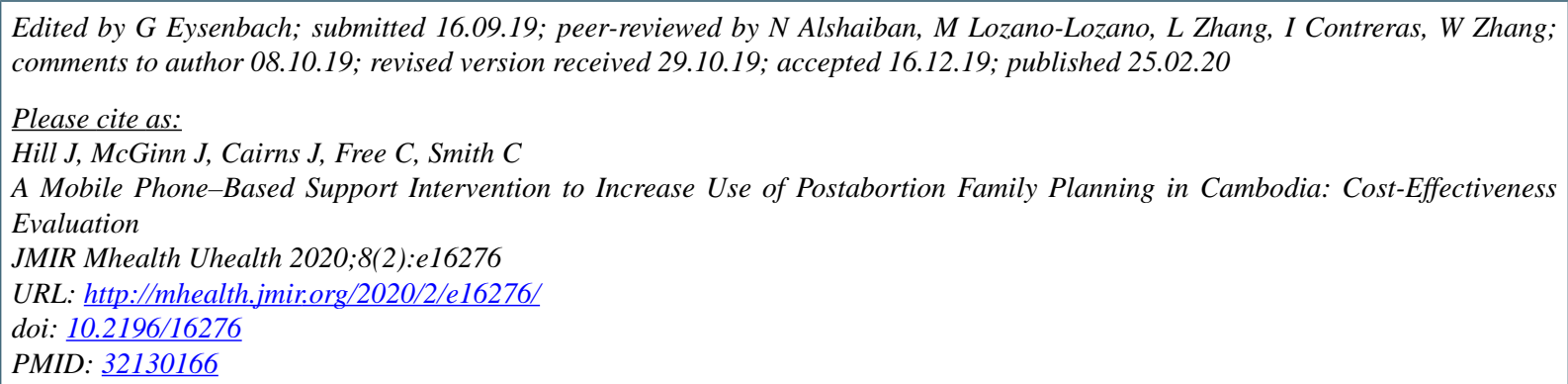

(CJeremy Hill, Jourdan McGinn, John Cairns, Caroline Free, Chris Smith. Originally published in JMIR mHealth and uHealth (http://mhealth.jmir.org), 25.02.2020. This is an open-access article distributed under the terms of the Creative Commons Attribution License (https://creativecommons.org/licenses/by/4.0/), which permits unrestricted use, distribution, and reproduction in any medium, provided the original work, first published in JMIR mHealth and uHealth, is properly cited. The complete bibliographic information, a link to the original publication on http://mhealth.jmir.org/, as well as this copyright and license information must be included. 